\title{
ANALISIS KEBUTUHAN AIR IRIGASI MENGGUNAKAN CROPWAT 8.0 PADA DAERAH IRIGASI KRUENG JREU KABUPATEN ACEH BESAR
}

(Analysis of Irrigation Water Requirement Using CROPWAT 8.0 in Krueng Jreu Irrigation Area of Aceh Besar Regency)

\author{
Mahendra Rizqi ${ }^{1}$, Muhammad Yasar ${ }^{1}$, Dewi Sri Jayanti ${ }^{1 *}$, \\ ${ }^{1}$ Program Studi Teknik Pertanian, Fakultas Pertanian, Universitas Syiah Kuala \\ *Corresponding author: dewisrijayanti@unsyiah.ac.id
}

\begin{abstract}
Abstrak. Salah satu usaha peningkatan produksi pangan khususnya padi adalah tersedianya air irigasi di areal sawah sesuai dengan kebutuhan. Kebutuhan air yang diperlukan pada areal irigasi besarnya bervariasi sesuai keadaan untuk memenuhi kebutuhan evapotranspirasi, kehilangan air, kebutuhan air untuk tanaman dengan memperhatikan jumlah air yang diberikan oleh alam melalui hujan dan kontribusi air tanah. Pengaplikasian CROPWAT 8.0 ini sangat membantu dalam pengelolaan data sehingga menghasilkan data yang dapat digunakan. Tujuan penelitian ini adalah untuk menghitung kebutuhan air irigasi pada Daerah Irigasi Krueng Jreu dengan menggunakan software CROPWAT 8.0. Metode penelitian adalah menentukan parameter, pengumpulan data dan pengolahan data. Data yang digunakan dalam penelitian ini adalah data luas areal yang dialiri, data-data untuk menghitung evapotranspirasi meliputi temperatur, kelembaban relatif, kecepatan angin, lama penyinaran matahari, curah hujan, pola dan jadwal tanam yang dianjurkan di daerah penelitian. Hasil penelitian yang telah dilakukan diperoleh Nilai evapotranspirasi potensial $\left(\mathrm{ET}_{0}\right)$ rata-rata di Daerah Irigasi Krueng Jreu adalah sebesar 3,75 mm/hari, curah hujan efektif $(\mathrm{Re})$ rata-rata di Daerah Irigasi Krueng Jreu adalah sebesar 3,09 $\mathrm{mm} /$ hari, kebutuhan air untuk penyiapan lahan adalah sebesar 11,35 $\mathrm{mm} /$ hari untuk Bulan November dan sebesar 11,71 mm/hari untuk Bulan Mei, kebutuhan bersih air di sawah (NFR) untuk padi rendeng dan padi gadu yaitu sebesar $11,22 \mathrm{~mm} / \mathrm{hari}$ dan $25,34 \mathrm{~mm} / \mathrm{hari}$, dan kebutuhan air pada pintu pengambilan (DR) untuk padi rendeng dan padi gadu yaitu sebesar 17,27 $\mathrm{mm} / \mathrm{hari}$ dan 38,98 $\mathrm{mm} / \mathrm{hari}$. Kebutuhan air irigasi di Darah Irigasi Krueng Jreu dengan total luas area sebesar 3.287 ha dengan kebutuhan air irigasi pola tanam padi-padi yang dimulai awal pengolahan lahan pada awal Bulan November maka didapatkan kebutuhan air irigasi maksimal yaitu terjadi pada Bulan Juli dengan perhitungan CROPWAT yaitu sebesar 14,9 $\mathrm{m}^{3} /$ detik dan untuk perhitungan manual yaitu sebesar $6,26 \mathrm{~m}^{3} /$ detik. Kebutuhan air irigasi minimum yaitu terjadi pada Bulan Desember dengan perhitungan CROPWAT yaitu sebesar $0,00 \mathrm{~m}^{3} / \mathrm{detik}$ dan perhitungan manual yaitu sebesar $0,45 \mathrm{~m}^{3} /$ detik.
\end{abstract}

Kata kunci : Irigasi, Kebutuhan air irigasi, CROPWAT, DAS Krueng Jreu

Abstract. One of the efforts to increase food production, especially rice, is the availability of irrigation water in paddy fields according to their needs. The required water needs in the area of irrigation varies according the State needs for evapotranspiration, water loss, water needs for plants with attention to the amount of water given by nature through the rain and the contribution of groundwater. The application of CROPWAT 8.0 is very helpful in managing data so as to produce data that can be used. The purpose of this study was to calculate irrigation water requirements in the Krueng Jreu Irrigation Area using CROPWAT 8.0 software. The research method is determining parameters, data collection and data processing. The data used in this study is the data area that is flowed, the data for calculating evapotranspiration include: temperature, relative humidity, wind speed, duration of solar radiation, rainfall, patterns and planting schedules recommended in the study area. Based on the results of the research that has been carried out, it can be concluded as follows: the average evapotranspiration value $\left(\mathrm{ET}_{0}\right)$ in the Krueng Jreu Irrigation Area is $3,75 \mathrm{~mm} /$ day, the effective rainfall $(\mathrm{Re})$ in the Krueng Jreu Irrigation Area is amounting to 3,09 mm/day, water requirements for land preparation of $11,35 \mathrm{~mm} /$ day in November and $11,71 \mathrm{~mm} /$ day in Mei, clean water requirements in rice fields (NFR) for rendeng rice and gadu rice which amounted to $11,22 \mathrm{~mm} /$ day and $25,34 \mathrm{~mm} /$ day, and water requirements on the retrieval gate (DR) for rendeng rice and gadu rice were equal to $17,27 \mathrm{~mm} /$ day and $38,98 \mathrm{~mm} /$ day. Irrigation water needs in Krueng Jreu Irrigation Blood with a total area of 3.287 ha with irrigation water requirements for rice-paddy cropping patterns that were started at the beginning of land processing at the beginning of November the maximum irrigation water needs were obtained in July with CROPWAT calculations that is equal to $14,9 \mathrm{~m}^{3} / \mathrm{second}$ and for manual calculations amounting to $6,26 \mathrm{~m}^{3} / \mathrm{sec}$. For 
minimum irrigation water needs, that occurs in December with a CROPWAT calculation is $0,00 \mathrm{~m}^{3} / \mathrm{second}$ and manual calculation of $0,45 \mathrm{~m}^{3} / \mathrm{sec}$.

Keywords: Irrigation, Irrigation water needs, CROPWAT

\section{PENDAHULUAN}

Indonesia adalah negara yang sebagian besar penduduknya hidup dari pertanian dengan makanan pokoknya bersumber dari beras, sagu, serta ubi hasil pertanian. Jumlah penduduk Indonesia diprediksi akan menjadi 275 juta jiwa pada tahun 2025, maka untuk memenuhi produksi bahan makanan pokok berupa padi, sangat diperlukan jaringan irigasi. Irigasi pendukung keberhasilan pembangunan pertanian merupakan kebijakan pemerintah yang sangat strategis dalam pertumbuhan perekonomian nasional guna mempertahankan produksi swasembada beras. Saat ini sekitar $80 \%$ dari produksi padi dalam negeri berasal dari sawah beririgasi, sementara program ketahanan pangan dapat terganggu dari banyaknya permasalahan yang menghambat kinerja dan keberlanjutan fungsi jaringan irigasi yang telah dibangun dengan tingkat kerusakan jaringan irigasi setiap tahunnya mencapai $100.000 \mathrm{Ha}$ dan pada tahun 2002 kerusakan mencapai $172.000 \mathrm{Ha}$ (Soenarno, 2004).

Salah satu usaha peningkatan produksi pangan khususnya padi adalah tersedianya air irigasi di sawahsawah sesuai dengan kebutuhan. Kebutuhan air yang diperlukan pada areal irigasi besarnya bervariasi sesuai keadaan. Kebutuhan air irigasi adalah jumlah volume air yang diperlukan untuk memenuhi kebutuhan evaporasi, kehilangan air, kebutuhan air untuk tanaman dengan memperhatikan jumlah air yang diberikan oleh alam melalui hujan dan kontribusi air tanah. Besarnya kebutuhan air irigasi juga bergantung kepada cara pengolahan lahan. Dalam merencanakan besarnya debit kebutuhan air yang diperlukan pada areal persawahan secara keseluruhan perlu dilakukan suatu analisa kebutuhan air mulai dari saluran pembawa yaitu saluran primer, saluran sekunder dan saluran tersier hingga besarnya kebutuhan di petak-petak sawah, dalam hal ini perlu didukung dengan kelengkapan data-data yang terkait dalam analisa ini untuk mendapatkan hasil yang optimal.

Dalam memenuhi kebutuhan air khususnya untuk kebutuhan air di persawahan maka perlu didirikan sistem irigasi dan bangunan bendung. Kebutuhan air di persawahan ini kemudian disebut dengan kebutuhan air irigasi.. Tujuan irigasi adalah untuk memanfaatkan air irigasi yang tersedia secara benar yakni seefisien dan seefektif mungkin agar produktivitas pertanian dapat meningkat sesuai yang diharapkan. Jumlah kebutuhan air untuk irigasi umumnya dipengaruhi oleh beberapa faktor, yaitu curah hujan, evapontranspirasi tanaman, jenis dan umur tanaman, sistem pemberian air dan sistem irigasi yang digunakan dan dinyatakan dalam ltr/dtk/ha. Sedangkan faktor lain yang menentukan adalah jenis tanah dan sifat fisik tanah serta faktor iklim dan keadaan topografi setempat (Arsyad,1989).

Pengetahuan tentang keirigasian terus berkembang sesuai dengan perkembangan ilmu pengetahuan secara umum. Masuknya era digital juga merambah pada ranah ilmu keirigasian. Perhitungan tentang keirigasian baik mulai dari kebutuhan air irigasi, kebutuhan air tanaman, hngga kebutuhan air pada suatu lahan dan lain sebagainya. Selain dapat dihitung dengan menggunakan rumus manual juga dapat dihitung dengan menggunakan software. Software yang digunakan pada penelitian ini adalah software CROPWAT 8.0. Kecamatan Indrapuri merupakan salah satu kecamatan yang sebahagian besar wilayahnya merupakan persawahan masyarakat. Dalam pemenuhan pengairan untuk persawahan mereka mengandalkan pengairan irigasi Krueng Jreu sebagai penyedia air utamanya. Luas total area daerah sub DAS irigasi Kueng Jreu yaitu 3.2867,66 Ha. Oleh karena itu, diperlukan suatu penelitian untuk mengetahui seberapa besar air irigasi yang diperlukan untuk memenuhi kebutuhan air areal persawahan tersebut. 


\section{METODE PENELITIAN}

Penelitian ini dilakukan di Kecamatan Indrapuri Kabupaten Aceh Besar, pada Bulan Januari 2018 sampai dengan selesai.

\section{DATA DAN METODE}

\section{Data}

Data-data yang digunakan dalam penelitian ini adalah data luas lahan sawah tahun 2017, curah hujan bulanan yang diperoleh dari Stasiun BMKG Indrapuri periode 2008 - 2017, data-data temperatur, kelembaban relatif, kecepatan angin, lama penyinaran matahari yang diperoleh dari Stasiun Badan Meteorologi dan Klimatologi Indrapuri periode $2008-2017$.

\section{Metode Penelitian}

Tahap-tahap yang dilaksanakan dalam menyelesaikan penelitian ini adalah menentukan parameter, pengumpulan data dan pengolahan data.

\section{Parameter}

Parameter yang dibutuhkan dalam penelitian ini adalah evapotranspirasi, curah hujan efektif, penggunaan konsumtif, perkolasi, kebutuhan untuk penyiapan lahan dan pola tanam.

\section{Pengolahan Data}

Pengolahan data dilakukan untuk mendapatkan hasil analisis parameter yang diperlukan untuk menetukan kebutuhan air irigasi yaitu menghitung evapotranspirasi potensial, penggunaan konsumtif, penentuan curah hujan efektif, perkolasi atau rembesan, penentuan penggantian lapisan, penentuan kebutuhan air selama pengolahan tanah, penentuan efesiensi irigasi, kebutuhan bersih air sawah, penentuan kebutuhan air di intake, dan kebutuhan air irigasi di sawah. Kemudian utuk perhitungan kebutuhan air irigasi dengan menggunakan CROPWAT sebagai perbandingan hasil perhitungan kebutuhan air irigasi.

\section{Evapotranspirasi Potensial}

Evapotranspirasi acuan (ET0) dihitung dengan menggunakan metoda Penman Modifikasi dari data-data yang tersedia pada stasiun klimatologi. Nilai koefisien $(\mathrm{Kc})$ tanaman dipilih berdasarkan tanaman yang dibudidayakan di Daerah Irigasi. Untuk menganalisa evapotranspirasi acuan (ET0) standar adalah menggunakan rumus Penman-Monteith yang telah dimodifikasi dan dikembangkan menjadi rumus FAO Penman-Monteith. Food and Agriculture Organization (FAO) merekomendasikan persamaan metode Penman sebagai metode yang cukup baik untuk memprediksikan besarnya ETo.

Adapun persamaan tersebut adalah (Hambali,2007) :

$$
\mathrm{ET}_{0}=\frac{0,408 \Delta(\mathrm{Rn}-\mathrm{G})+\gamma_{\mathrm{T}+273} \mathrm{900} \mathrm{U} 2(\mathrm{es}-\mathrm{ea})}{\Delta+\gamma(1+0,34 \mathrm{U} 2)}
$$

Dimana :

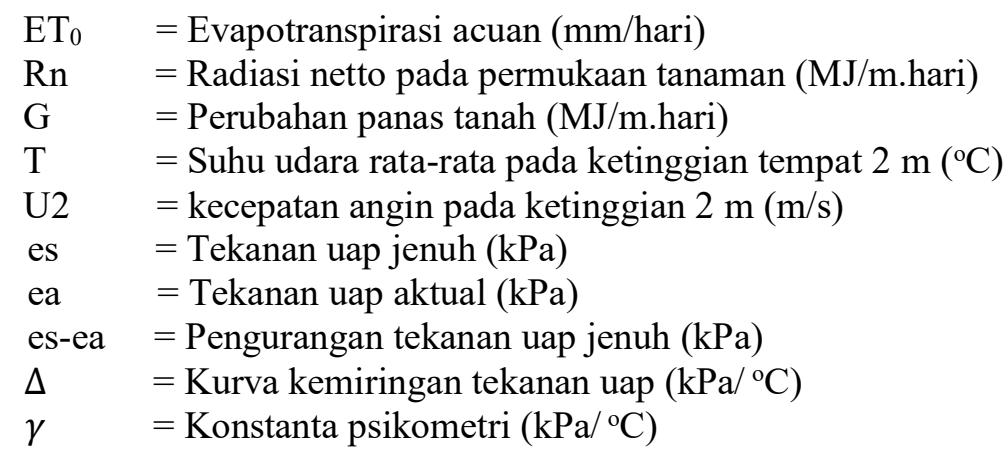




\section{Penggunaan Konsumtif}

Penggunaan konsumtif (ETc) adalah jumlah air yang dipakai oleh tanaman untuk proses fotosintesis dari tanaman tersebut. Penggunaan konsumtif dihitung dengan rumus berikut (Doorenbos dan Pruitt, 1984) :

$$
\mathrm{ETc}=\mathrm{Kc}_{\mathrm{xET}}
$$

Dimana :

Kc $=$ Koefisien tanaman

$\mathrm{ET}_{0}=$ Evapotranspirasi potensial (Penman modifikasi) $(\mathrm{mm} / \mathrm{hari})$

\section{Curah Hujan Efektif}

Curah hujan efektif (Re) rata-rata bulanan dihitung dengan menggunakan persamaan Oldeman dan Syarifuddin (1977) :

$$
\mathrm{Re}=1,0(0,82 \mathrm{Rm}-30) \mathrm{mm} / \mathrm{hari} \text { (padi sawah) }
$$

Dimana :

$\operatorname{Re} \quad=$ Curah hujan efektif ( $\mathrm{mm} / \mathrm{hari})$

$\mathrm{Rm} \quad=$ Curah hujan bulanan ( $\mathrm{mm} / \mathrm{hari})$

\section{Perkolasi dan Rembesan}

Pada tanah-tanah lempung berat dengan karakteristik pengolahan (puddling) yang baik, laju perkolasi dapat mencapai 1-3 mm/ hari. Pada tanah-tanah yang lebih ringan laju perkolasi dapat lebih tinggi (Soemarto, 1986).

\section{Penentuan Penggantian Lapisan (WLR/Water Layer Requirment)}

Kebutuhan air untuk mengganti lapisan air ditetapkan berdasarkan Direktorat Jenderal Pengairan (1986). Besar kebutuhan air untuk penggantian lapisan air adalah $50 \mathrm{~mm} /$ bulan (atau $1,7 \mathrm{~mm} / \mathrm{hari}$ ) pada waktu sebulan dan dua bulan setelah transplantasi.

\section{Penentuan Kebutuhan Air Selama Pengolahan Tanah (IR)}

Analisis kebutuhan air selama pengolahan lahan dapat menggunakan metode seperti diusulkan oleh Van de Goor dan Ziljstra (1968) sebagai berikut :

$$
\begin{aligned}
& \mathrm{IR}=\mathrm{M} \mathrm{e} /\left(\mathrm{e}^{\mathrm{k}}-1\right) \\
& \mathrm{M}=\mathrm{Eo}+\mathrm{P} \\
& \mathrm{K}=\mathrm{M} \mathrm{T} / \mathrm{S}
\end{aligned}
$$

Dimana :

IR $=$ Kebutuhan air untuk pengolahan lahan $(\mathrm{mm} / \mathrm{hari})$

$\mathrm{M}=$ Kebutuhan air untuk mengganti kehilangan air akibat evaporasi dan perkolasi di sawah yang sudah dijenuhkan (mm/hari)

Eo $\quad=$ Evaporasi potensial $(\mathrm{mm} / \mathrm{hari})$

$\mathrm{P} \quad=$ Perkolasi $(\mathrm{mm} / \mathrm{hari})$

$\mathrm{k} \quad=$ Konstanta

$\mathrm{T} \quad=$ Jangka waktu pengolahan (hari)

$\mathrm{S} \quad=$ Kebutuhan air untuk penjenuhan $(\mathrm{mm})$

e $\quad=$ Bilangan eksponen: 2,7182

\section{Penentuan Efisiensi Irigasi}

Mengacu pada Pedoman Direktorat Jenderal Pengairan (1986) efisiensi irigasi diambil $90 \%$ dan tingkat tersier $80 \%$. Angka efisiensi irigasi keseluruhan tersebut dihitung dengan cara mengkonversi efisiensi di masing-masing tingkat yaitu $0,9 \times 0,9 \times 0,8=0,648 \approx 65 \%$.

\section{Kebutuhan Bersih Air Sawah (NFR/Net Field Requirement)}

Kebutuhan bersih untuk air tanaman padi di sawah terbagi atas (Direktorat Jenderal Pengairan, 1986) :

Untuk penyiapan lahan dihitung dengan persamaan : 


$$
\mathrm{NFR}=\mathrm{ETc}-\mathrm{Re}
$$

Untuk pertumbuhan padi dihitung dengan persamaan :

$$
\mathrm{NFR}=\mathrm{ETc}+\mathrm{P}-\mathrm{Re}+\mathrm{WLR}
$$

Dimana :

$$
\begin{array}{ll}
\text { NFR } & =\text { Kebutuhan bersih air di sawah }(\mathrm{mm} / \text { hari }) \\
\mathrm{Re} & =\text { Curah hujan efektif }(\mathrm{mm} / \mathrm{hari}) \\
\mathrm{ETc} & =\text { Evapotranspirasi tanaman }(\mathrm{mm} / \text { hari }) \\
\mathrm{P} & =\text { Perkolasi (mm/hari) } \\
\text { WLR } & =\text { Pergantian lapisan air }(\mathrm{mm} / \text { hari) }
\end{array}
$$

\section{Penentuan Kebutuhan Air di Intake}

Kebutuhan air di pintu pengambilan dihitung dengan persamaan (Departemen Pekerjaan Umum, 1986) :

$$
\mathrm{DR}=\frac{N F R}{\text { Eff primer } x \text { Eff sekunder } x \text { Eff tersier }}
$$

Dimana :

DR $=$ Kebutuhan air pada pintu pengambilan ( $\mathrm{mm} / \mathrm{hari})$

NFR = Kebutuhan bersih air di sawah ( $\mathrm{mm} /$ hari)

Eff $\quad=$ Efisiensi saluran tersier, saluran sekunder dan primer

\section{.Kebutuhan Air Irigasi di Sawah}

Menurut Triatmodjo (2008), kebutuhan air irigasi dihitung dengan persamaan berikut :

$$
K A I=\frac{E T_{c}+I R+W L R+P-R_{e}}{E I} x A
$$

Dimana :

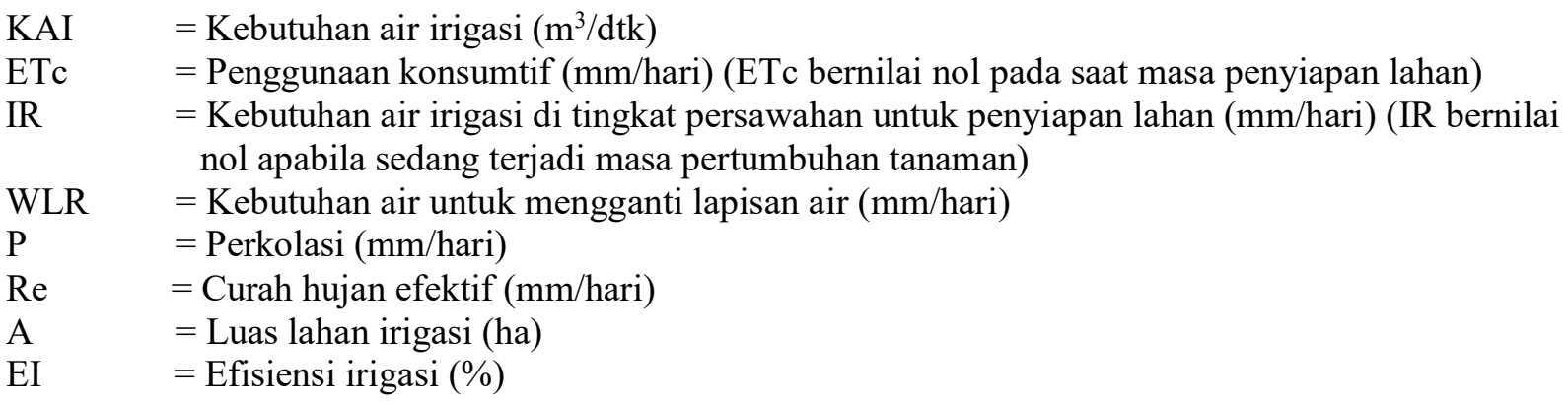

\section{HASIL DAN PEMBAHASAN}

\section{Evapotranspirasi Potensial}

Nilai evapotranspirasi potensial yang diperoleh pada setiap bulannya didapatkan nilai yang berbedabeda karena dipengaruhi oleh faktor penyinaran matahari, suhu, kelembaban udara dan kecepatan angin. Secara umum besarnya ET0 akan meningkat ketika radiasi panas matahari, suhu, kelembaban, dan kecepatan angin bertambah besar. Perbandingan nilai evapotranspirasi potensial hasil perhitungan CROPWAT dan manual dapat dilihat pada Gambar 1. 


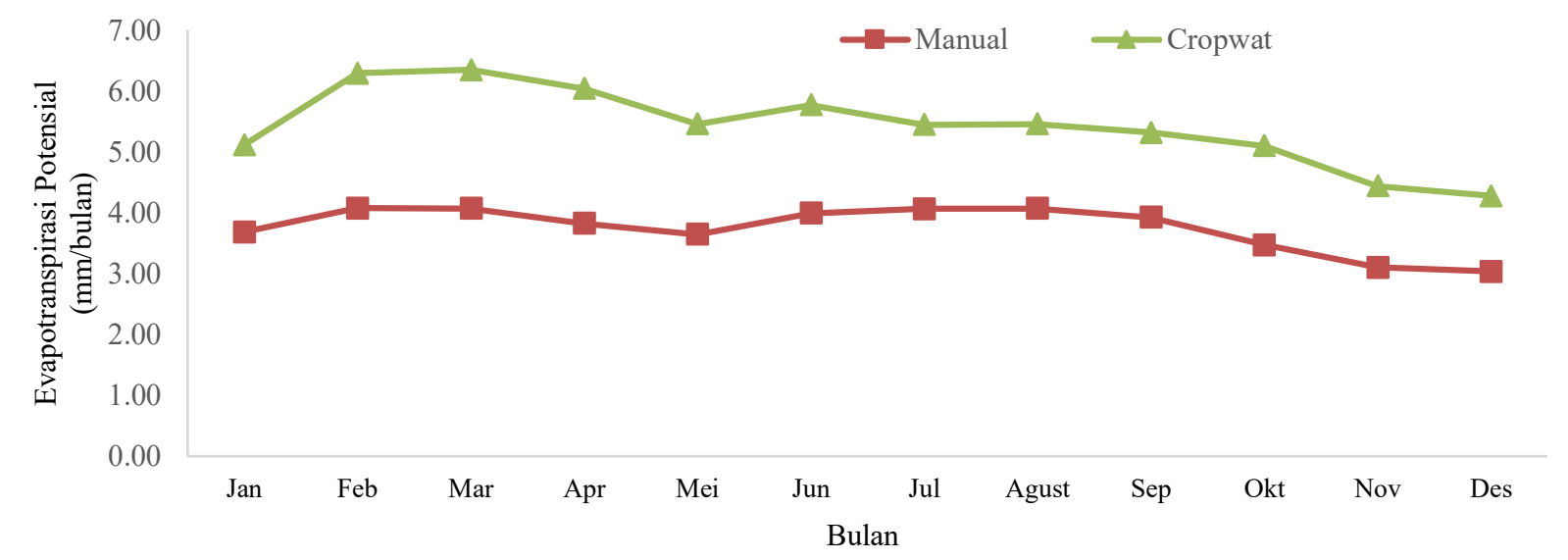

Gambar 1. Perbandingan nilai $\mathrm{ET}_{0} \mathrm{CROPWAT}_{\text {dengan }} \mathrm{ET}_{0}$ Manual

Berdasarkan grafik diatas dapat disimpulkan bahwa nilai evapotranspirasi potensial perhitungan secara CROPWAT dan manual nilai maksimum terjadi pada Bulan Februari dan nilai minimum terjadi pada Bulan Desember. Berdasarkan grafik tersebut dapat dilihat bahwa pada musim penghujan (Oktober - Maret), nilai kebutuhan air cenderung meningkat. Sementara itu, pada musim kemarau (April - September), kebutuhan air tanaman cenderung menurun. Hal tersebut menandakan bahwa kebutuhan air tanaman bergantung pada kondisi iklim pada wilayah tersebut, selain dari faktor-faktor lainnya seperti faktor karakteristik tanaman, kondisi lahan, dan faktor budidaya.

\section{Penggunaan Konsumtif Tanaman (ETc)}

Penentuan nilai penggunaan konsumtif tanaman (ETc) berdasarkan besarnya evapotranpirasi potensial $\left(\mathrm{ET}_{0}\right)$ dengan nilai koefisien tanaman $(\mathrm{Kc})$ pada kondisi pertumbuhan tanaman yang tidak terganggu. Hasil perhitungan nilai penggunaan konsumtif tanaman untuk padi rendeng dan padi gadu dapat dilihat pada Tabel 1 .

Tabel 1. Nilai ETc pada Padi Rendeng dan Padi Gadu

\begin{tabular}{lcccc}
\hline \multirow{2}{*}{$\begin{array}{c}\text { Jenis } \\
\text { Tanaman }\end{array}$} & \multicolumn{3}{c}{ ETc (mm/hari) } & Total \\
\cline { 2 - 4 } & I (Vegetatif) & II (Generatif) & III (Panen) & \\
\hline Padi Rendeng & 3,34 & 8,15 & 3,87 & 15,36 \\
Padi Gadu & 4,40 & 10,18 & 3,92 & 18,50 \\
\hline
\end{tabular}

Sumber : Hasil Analisis, (2018)

Berdasarkan tabel di atas dapat dijelaskan bahwa nilai penggunaan konsumtif tanaman tertinggi terdapat pada tanaman padi gadu yaitu pada fase generatif. Hal ini disebabkan nilai Kc pada fase generatif lebih tinggi dari pada fase vegetatif dan fase panen sehingga kebutuhan air tanamannya lebih besar. Nilai ETc dipengaruhi oleh evapotranspirasi potensial dan koefisien tanaman serta karakteristik tanaman pada fase pertumbuhan dan juga kondisi iklim secara umum.

\section{Curah Hujan Efektif}

Curah hujan efektif sangat mempengaruhi kebutuhan air irigasi, dimana curah hujan efektif merupakan curah hujan yang jatuh selama periode pertumbuhan tanaman dan dapat digunakan oleh tanaman untuk memenuhi kebutuhan air tanaman. Dengan adanya curah hujan efektif maka sebagian kebutuhan air tanaman akan terpenuhi sehingga kebutuhan air irigasi akan berkurang dan air yang tersedia dapat disimpan untuk kebutuhan berikutnya. Hasil perhitungan curah hujan efektif secara CROPWAT dan manual dapat dilihat pada Gambar 2. 


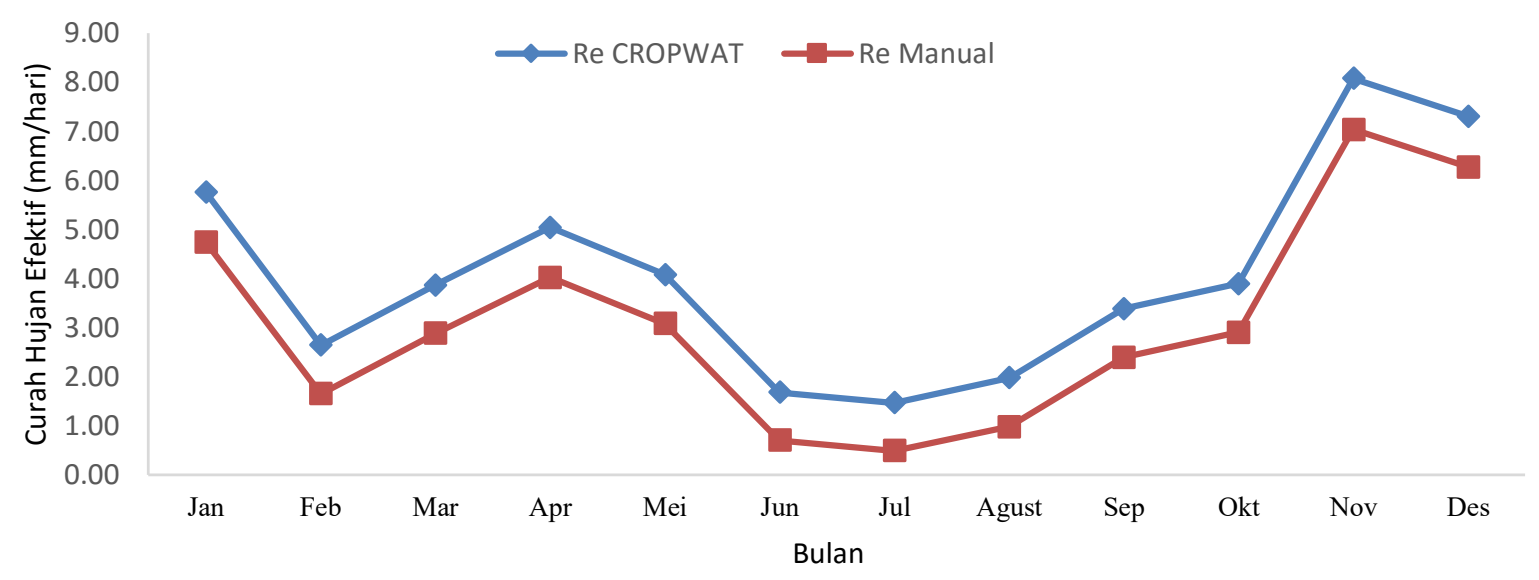

Gambar 2. Perbandingan nilai Re manual dengan Re CROPWAT

Berdasarkan grafik diatas dapat disimpulkan bahwa curah hujan efektif maksimum terjadi pada Bulan November dan curah hujan efektif minimum terjadi pada Bulan Juli. Perbedaan nilai curah hujan efektif pada setiap bulannya berbeda karena dipengaruhi oleh curah hujan, apabila intensitas curah hujannya tinggi maka curah hujan efektif juga tinggi dan sebaliknya apabila intensitas curah hujannya rendah maka curah hujan efektifnya juga rendah.. Curah hujan memberikan kontribusi yang besar untuk memenuhi kebutuhan air tanaman, pada musim hujan sebagian besar kebutuhan air dapat dipenuhi oleh air hujan. Sementara pada musim kemarau kebutuhan air irigasi yang tidak dapat terpenuhi oleh air hujan dapat dipenuhi dengan adanya irigasi. Besarnya jumlah air yang bersumber dari curah hujan sulit untuk diperkirakan, karena curah hujan sangat bervariasi setiap tahunnya. Curah hujan yang jatuh tidak semuanya digunakan oleh tanaman. Sebagian hujan hilang karena limpasan permukaan (run off) atau karena perkolasi. Jumlah curah hujan yang jatuh dan efesien untuk pertumbuhan tanaman tergantung pada intensitas hujan, topografi lahan, sistem penanaman dan fase pertumbuhan.

\section{Kebutuhan Air Untuk Pengolahan Tanah}

Berdasarkan Departemen Pekerjaan Umum (1986), besarnya kebutuhan air untuk penyiapan lahan pada tanah bertekstur berat tanpa retak- retak diambil $200 \mathrm{~mm}$, ini termasuk penjenuhan dan penyiapan lahan. Pada saat transplantasi (tanam) tidak perlu ada lapisan air di areal sawah. Setelah transplantasi selesai lapisan air di sawah akan ditambah sebesar $50 \mathrm{~mm}$. Secara keseluruhan air yang diperlukan adalah sebesar $250 \mathrm{~mm}$ untuk penyiapan lahan dan untuk lapisan awal setelah transplantasi. Lama waktu yang diperlukan untuk penyiapan lahan/menggarap sawah seluruh petak tersier dengan menggunakan traktor tangan (hand tractor) \pm 30 hari. Hasil perhitungan kebutuhan air untuk penyiapan lahan pada Daerah Irigasi (D.I) Krueng Jreu Kabupaten Aceh Besar adalah sebesar 11,35 mm/hari untuk Bulan November dan sebesar 11,71 mm/hari untuk Bulan Mei.

\section{Kebutuhan Air di Sawah (NFR/Net Field Requirement)}

Kebutuhan air disawah dipengaruhi oleh faktor-faktor cara penyiapan lahan, kebutuhan air tanaman, perkolasi dan rembesan, penggantian lapisan air dan curah hujan efektif. Besarnya kebutuhan air disawah bervariasi menurut tahap pertumbuhan tanaman dan bergantung kepada cara pengolahan lahan. Rata-rata hasil perhitungan kebutuhan air di sawah pada Daerah Irigasi dapat dilihat pada Tabel 2.

Tabel 2. Kebutuhan Air Rata-rata di Sawah

\begin{tabular}{lcccc}
\hline \multirow{2}{*}{ Jenis Tanaman } & \multicolumn{3}{c}{ Kebutuhan Air di Sawah (mm/hari) } & \multirow{2}{*}{ Total } \\
\cline { 2 - 4 } & I (Vegetatif) & II (Generatif) & III (Panen) & \\
\hline Padi Rendeng & 0,77 & 7,46 & 2,99 & 11,22 \\
Padi Gadu & 7,4 & 14,41 & 3,53 & 25,34 \\
\hline
\end{tabular}

Sumber : Hasil Analisis, (2018).

Berdasarkan tabel di atas dapat dijelaskan bahwa kebutuhan air rata-rata di sawah pada Daerah Irigasi Krueng Jreu untuk masing-masing jenis padi bervariatif. Untuk padi rendeng pada tahap vegetatif membutuhkan air lebih banyak daripada tahap generatif dan panen, karena ditanam pada musim penghujan 
sehingga proses penguapan lebih sedikit dan juga air yang digunakan oleh tanaman padi terserap dengan baik untuk pertumbuhan padi. Sedangkan untuk padi gadu membutuhkan air lebih banyak pada tahap generatif daripada tahap vegetatif dan panen, karena penanaman padi gadu dilakukan pada musim kemarau sehingga air yang dibutuhkan terbagi untuk pertumbuhan padi dan proses penguapan.

\section{Kebutuhan Air di Intake}

Kebutuhan air di intake ini dihitung dengan membandingkan kebutuhan bersih air di sawah yang sudah dihitung dengan efesiensi saluran. Hasil perhitungan kebutuhan air rata-rata pada pintu penyadapan atau pengambilan dapat dilihat pada Tabel 3.

Tabel 3. Kebutuhan Air di Intake

\begin{tabular}{lcccc}
\hline \multirow{2}{*}{ Jenis Tanaman } & \multicolumn{3}{c}{ Kebutuhan Air di Intake (mm/hari) } & \multirow{2}{*}{ Total } \\
\cline { 2 - 4 } & I (Vegetatif) & II (Generatif) & III (Panen) & \\
\hline Padi Rendeng & 1,19 & 11,49 & 4,59 & 17,27 \\
Padi Gadu & 11,38 & 22,17 & 5,43 & 38,98 \\
\hline
\end{tabular}

Sumber : Hasil Analisis, (2018).

Kebutuhan air total pada pintu pengambilan yang terjadi di Daerah Irigasi Krueng Jreu pada musim tanam gadu yaitu sebesar $38,98 \mathrm{~mm} /$ hari dan pada musim tanam rendeng yaitu sebesar 17,27 mm/hari. Hal ini disebabkan karena musim tanam gadu penyinaran mataharinya lebih lama dibandingkan musim tanam rendeng yang lebih banyak curah hujannya. Perbedaan nilai pada setiap fase dipengaruhi oleh nilai kc tanaman yang berbeda pada setiap fase pertumbuhannya. Untuk Kebutuhan air paling banyak terdapat pada fase generatif masing-masing musim tanam, hal ini disebabkan pada tahap generatif lebih banyak memerlukan air.

\section{Kebutuhan Air Irigasi di Sawah}

Kebutuhan air irigasi adalah jumlah volume air yang diperlukan untuk memenuhi kebutuhan evapotranspirasi, kehilangan air, kebutuhan air untuk tanaman selama proses pertumbuhannya. Hasil perhitungan kebutuhan air rata-rata di irigasi dapat dilihat pada Tabel 3.

Tabel 4. Kebutuhan Air Irigasi

\begin{tabular}{clcc}
\hline Musim Tanam & Bulan & $\begin{array}{c}\text { Kebutuhan Air Irigasi } \\
\left(\mathrm{m}^{3} / \mathrm{det}\right)\end{array}$ & $\begin{array}{c}\text { Kebutuhan Air Irigasi } \\
\left(\mathrm{m}^{3} / \mathrm{det}\right)(\mathrm{CROPWAT})\end{array}$ \\
\hline & November & 3,94 & 13,27 \\
& Desember & 0,45 & 0,00 \\
Rendeng & Januari & 1,66 & 0,36 \\
& Februari & 2,71 & 3,35 \\
& Maret & 1,75 & 0,00 \\
\hline Bera & April & 0,00 & 14,9 \\
& Mei & 6,26 & 5,27 \\
& Juni & 4,33 & 5,77 \\
& Juli & 4,86 & 5,21 \\
& Agustus & 3,58 & 1,95 \\
\hline & September & 2,07 & 0,00 \\
\hline
\end{tabular}

Sumber : Hasil Analisis, (2018).

Berdasarkan tabel di atas dapat dijelaskan bahwa dengan luas wilayah Daerah Irigasi Krueng Jreu sebesar 3.287,66 ha dengan kebutuhan air irigasi pola tanam padi-padi yang dimulai awal pengolahan lahan pada awal Bulan November untuk musim tanam rendeng dan Bulan Mei untuk musim tanam gadu maka didapatkan kebutuhan air irigasi maksimal yaitu terjadi pada Bulan Juli dengan perhitungan manual yaitu sebesar 6,26 m3/detik dan untuk perhitungan CROPWAT yaitu sebesar 14,9 m3/detik. Untuk kebutuhan air irigasi minimum yaitu terjadi pada Bulan Desember dengan perhitungan manual yaitu sebesar $0,45 \mathrm{~m} 3 /$ detik dan perhitungan CROPWAT yaitu sebesar $0,00 \mathrm{~m} 3 /$ detik. 
Musim tanam rendeng penanamannya dilakukan pada tanggal 1 Desember hingga panen dilakukan Maret dibutuhkan air irigasi sebesar 10,51 m3/detik dengan perhitungan manual dan sebesar 19,08 m3/detik dengan menggunakan CROPWAT. Sedangkan untuk musim tanam gadu yang penanamannya dilakukan pada tanggal 1 Bulan Juni hingga panennya dilakukan pada Bulan September dibutuhkan air irigasi sebesar 21,11 $\mathrm{m} 3 /$ detik dengan perhitungan manual dan sebesar 33,10 m3/detik dengan menggunakan CROPWAT. Perbedaan nilai kebutuhan air irigasi antara musim tanam rendeng dan musim gadu ini dikarenakan bedanya musim tanam, sehingga kebutuhannya lebih besar pada musim tanam gadu karena ditanam pada musim kemarau. Kebutuhan irigasi pada Bulan Desember dengan menggunakan CROPWAT didapatkan sebesar 0 $\mathrm{m} 3$ /detik, ini disebabkan karena pada bulan tersebut kebutuhan air irigasinya terpenuhi dengan curah hujan efektif. Bulan April dan Oktober tidak memerlukan air irigasi karena pada kedua bulan tersebut areal sawah diberakan, sehingga pada saat bera tidak perlu dialiri irigasi.

Faktor yang membedakan hasil perhitungan CROPWAT dengan manual adalah data karakteristik tanaman dan jenis tanah yang ada pada CROPWAT yang telah tersedia dari FAO. Data karateristik tanaman pada CROPWAT juga menggunakan data Kc tanaman, lama tahapan, kedalaman perakaran, kedalaman pelumpuran, tinggi tanaman maksimum, tingkat deplesi (f) dan respon hasil (Ky). Nilai untuk Kc tanamannya terbagi dua, yaitu Kc basah dan Kc kering. Perbedaan Jenis tanah pada CROPWAT menggunakan data kadar air tersedia, tingkat infiltrasi maksimum, kedalaman akar maksimum, penipisan kelembaban tanah awal, kelembaban awal tersedia, porositas pengeringan, penipisan kritis untuk pemecahan genangan, perkolasi maksimum setelah penggenangan, ketersediaan air saat tanam, dan kedalaman air maksimum. Sedangkan untuk perhitungan kebutuhan air irigasi secara manual tidak menggunakan data-data tersebut.

\section{KESIMPULAN DAN SARAN}

Kebutuhan air irigasi di Darah Irigasi Krueng Jreu dengan total luas area sebesar 3.287,66 ha dengan kebutuhan air irigasi pola tanam padi-padi yang dimulai awal pengolahan lahan pada awal Bulan November maka didapatkan kebutuhan air irigasi maksimal yaitu terjadi pada Bulan Juli dengan perhitungan CROPWAT yaitu sebesar 14,9 $\mathrm{m}^{3} /$ detik dan untuk perhitungan manual yaitu sebesar $6,26 \mathrm{~m}^{3} /$ detik. Kebutuhan air irigasi minimum yaitu terjadi pada Bulan Desember dengan perhitungan CROPWAT yaitu sebesar $0,00 \mathrm{~m}^{3} / \mathrm{detik}^{\mathrm{dan}}$ perhitungan manual yaitu sebesar $0,45 \mathrm{~m}^{3} /$ detik. Perlu adanya penelitian lebih lanjut agar dapat menentukan ketersediaan air irigasi di Krueng Jreu sehingga diketahui besarnya debit air di Daerah Irigasi Kreung Jreu mencukupi untuk lahan pertanian atau tidak. 


\section{DAFTAR PUSTAKA}

Arsyad, S. 1989. Konservasi Tanah dan Air. IPB, Bogor.

Departemen Pekerjaan Umum. 1986. Standart Perencanaan Irigasi KP 01, 02, 04, dan 06. Badan Penerbit Pekerjaan Umum, Jakarta.

Direktorat Jendral Pengairan. 1986. Standar Perencanaan Irigasi (KP. 01-05). Departemen Pekerjaan Umum. CV Galang Persada, Bandung.

Doorenboss, J. and W.O, Pruitt. 1984. Crop Water Requirements. Food and Agriculture Organization of The United Nation, Rome.

Hambali, R. 2007. Materi Kuliah Hidrologi Lanjut. Sekolah Pascasarjana Jurusan Teknik Sipil Universitas Gadjah Mada, Yogyakarta.

Oldeman, L.R. dan D. Syarifuddin. 1977. An Agroclimatic Map of Sulawesi. Central Research Institute for Agriculture, Bogor.

Soemarto, C.D. 1986. Hidrologi Teknik Edisi 1. Usaha Nasional, Surabaya.

Soenarno. 2004. Tiga Program Pokok Untuk Ketahanan Pangan. Media Informasi Sumber Daya Air Departemen Pekerjaan Umum, Jakarta.

Triatmodjo, B. 2008. Hidrologi Terapan. Beta Offside, Yogyakarta.

Van de Goor G.A.W. dan G. Zijlstra. 1968. Irrigation requirements for double cropping of lowland rice in Malaya. ILRI Publication 14, Wageningen. 